\title{
Influence of Waterproof Covering on Finger Skin Temperature and Hand Pain during Immersion Test for Diagnosing Hand-arm Vibration Syndrome
}

\author{
Kumiko SUIZU, Masaiwa INOUE, Takae FUJIMURA, Hideko MORITA, \\ Junko INAGAKI, Hirohiko KAN and Noriaki HARADA*
}

Department of Hygiene, Yamaguchi University School of Medicine, Ube, Yamaguchi 755-8505, Japan

Received March 20, 2003 and accepted October 31, 2003

\begin{abstract}
The purpose of this study was to examine the influence of waterproof covering on finger skin temperature (FST) and hand pain during immersion test for diagnosing hand-arm vibration syndrome complying with the proposal of the International Organization for Standardization (ISO/ CD14835-1, 2001) for measurement procedure. Six healthy male subjects took part in the immersion tests and immersed their both hands into water at $12^{\circ} \mathrm{C}$ for $5 \mathrm{~min}$, repeatedly with two types of waterproof covering (polyethylene and natural rubber gloves) or without hand covering (bare hands) during immersion. The FST data from middle fingers and subjective pain scores for hand pain were analyzed. Statistically significant differences in FST among three conditions were observed showing the highest FST with natural rubber gloves, followed by the FST with polyethylene gloves and the lowest with bare hands. Significant differences in pain score among three conditions were observed during immersion showing the lowest pain score with natural rubber gloves, followed by the pain score with polyethylene gloves and the highest with bare hands. Immersion test with polyethylene gloves instead of bare hands during immersion seems to be suitable for reducing subject suffering.
\end{abstract}

Key words: Immersion test, Waterproof covering, Finger skin temperature, Pain scale, Subject suffering

Immersion tests are used for evaluating vascular disorders of the hand-arm vibration syndrome (HAVS). The value of such tests based on finger skin temperature (FST) measurement has been investigated. However, there is a wide difference in the test conditions among countries and researchers ${ }^{1-3)}$. Immersion tests with use of water at temperatures between $5^{\circ} \mathrm{C}$ and $15^{\circ} \mathrm{C}$ have been reported. Immersion time less than 5 min might be too short to obtain sufficient severity of cold-stress. Therefore, a water temperature of $12^{\circ} \mathrm{C}$ and an immersion period of $5 \mathrm{~min}$ are proposed at present for the standard method parameters to provide useful measurements while minimizing stress ${ }^{4)}$. Other conditions such as room temperature, season, subject preparation, etc., have also been described in the proposal within the International Organization for Standardization

\footnotetext{
*To whom correspondence should be addressed.
}

$(\mathrm{ISO} / \mathrm{CD} 14835-1,2001)^{4)}$. It has been pointed out in the ISO/CD14835-1, 2001 that the use of waterproof covering during immersion tests will prevent cooling of the hands after removal from the water due to evaporation ${ }^{4)}$. Waterproof covering might have influence on FST and hand pain during immersion test. A few report concerning the use of waterproof covering at immersion is found ${ }^{5,6}$. Usually, waterproof covering at immersion during immersion test has not been used in Japan. In this study we investigated the influence of waterproof covering on FST and subjective hand pain during immersion test. Measurements during immersion tests were performed according to ISO/CD14835-1. Six healthy male subjects who were medical students (age range: 20 to 23 , BMI: $21.0 \pm 1.9$ ) volunteered for the experiment. They immersed their both hands into water at $12 \pm 0.5^{\circ} \mathrm{C}$ for $5 \mathrm{~min}$, repeatedly with two types of waterproof covering, polyethylene gloves (SD glove, Sanko, Japan; weight- 2.75 


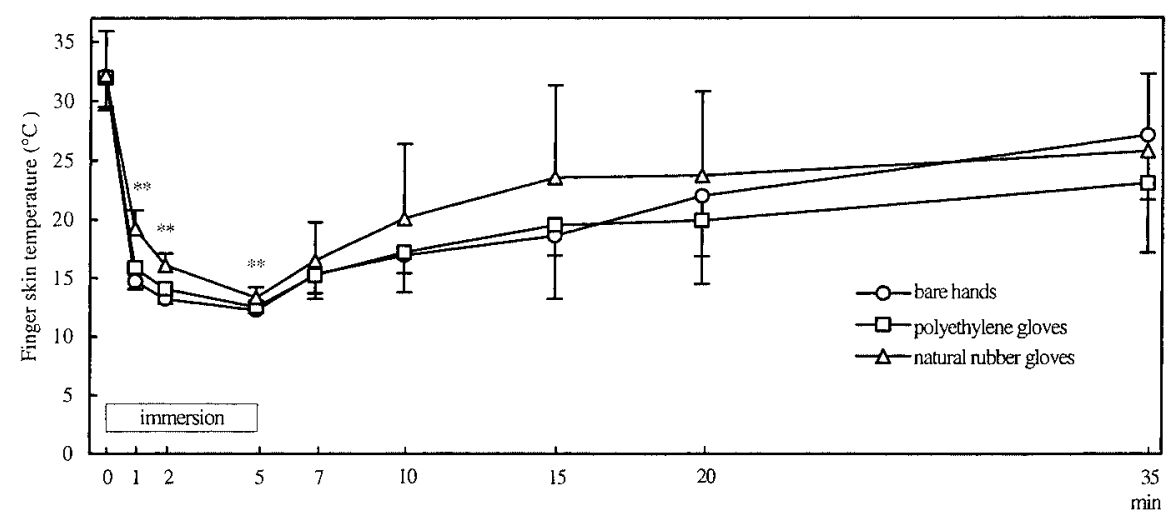

Fig. 1. Finger skin temperature of the left middle finger during immersion tests with bare hands, polyethylene gloves, and natural rubber gloves at immersion.

Pre-immersion $5^{\text {th }}$ min recording is shown as 0 in $\mathrm{x}$-axis. Data are mean $\pm \mathrm{SD}$. ${ }^{* *}: p<0.01$ (among three conditions).

$\mathrm{g}$, thinness- $0.03 \mathrm{~mm}$ and length- $29 \mathrm{~cm}$ ) and natural rubber gloves (Saniment glove, Luchi, Japan; weight- $8.5 \mathrm{~g}$, thinness$0.22 \mathrm{~mm}$ and length- $24.5 \mathrm{~cm}$ ) or without hand covering (bare hands). The both gloves were of large size, which were slightly larger than subject's hand size and well-fitted when were put on the hands.

The waterproof covering was put on just before immersion of the hands and was removed at the end of the immersion period. The FST of all fingers of the hand were measured and recorded at each minute for $40 \mathrm{~min}$ from pre-immersion to post-immersion. Sensors of thermometry were such attached to the ventral side of the distal phalanges of ten fingers with adhesive tape without any overlapping or severe tape tension that no blood occlusion was occurred due to the procedure. The FST data were analyzed for several points: pre-immersion ( 0 -min point; data at $5^{\text {th }}$ min recording before immersion), during immersion (at 1-, 2-, and 5-min points), and during recovery (at 7-, 10-, 15-, 20-, and 35-min points). Subjective pain scores for hand pain during immersion tests were evaluated at the same points using a questionnaire on a pain scale from 1 (none), to 2 (weak), 3 (moderate), 4 (strong), and 5 (extreme). The examination room was kept at $21 \pm 1{ }^{\circ} \mathrm{C}$. The season was autumn (October and November) and the average outdoor temperature was $15.8 \pm 3.5^{\circ} \mathrm{C}$.

Before examination, each subject rested for $30 \mathrm{~min}$ in the test room and put on four items of clothing (two each for upper and lower body) together with socks. All the subjects were requested to avoid smoking and use of any drug stimulants from $3 \mathrm{~h}$, and alcohol drinking from $12 \mathrm{~h}$ prior to the examination. The time $1 \mathrm{~h}$ before and $4 \mathrm{~h}$ after meal taken by the subjects was avoided for setting examination periods. These experiments were carried out between 10:00 to 17:00, and the time of the day to start the examinations was the same for a subject in the following days as it was in the first day for the individual subject. For measuring FST, digital thermometers (D-925, Takara, Japan) were used.

Two-way analysis of variance was performed to determine independent influence of covering conditions or of subjects on FST at each analyzed point. The differences in pain score were compared among the three conditions using Friedman test. Statistical procedures were done using SPSS statistical package program for Windows ${ }^{7}$. A $p<0.05$ was chosen for statistical significance.

Fig. 1 shows the FST of the left middle finger during immersion tests with different conditions. A significant influence of conditions on FST at 1-, 2- and 5-min points ( $\mathrm{p}<0.01$, respectively) during immersion was observed showing the highest FST with natural rubber gloves (19.2 \pm 1.6, $16.1 \pm 1.0$ and $13.4 \pm 0.9^{\circ} \mathrm{C}$ at 1 -, 2 - and 5-min points, respectively), followed by the FST with polyethylene gloves $\left(15.9 \pm 1.2,14.1 \pm 0.6\right.$ and $12.6 \pm 0.4^{\circ} \mathrm{C}$ at $1-, 2-$ and 5 -min points, respectively) and the lowest with bare hands (14.7 \pm $0.7,13.2 \pm 0.4$ and $12.3 \pm 0.2^{\circ} \mathrm{C}$ at 1 -, 2 - and 5-min points, respectively).

Fig. 2 shows the FST of the right middle finger during immersion tests with different conditions. A significant influence of conditions on FST at 1-, 2- and 5-min points ( $\mathrm{p}<0.01$, respectively) during immersion was observed showing the highest FST with natural rubber gloves (19.2 \pm $1.5,16.3 \pm 1.1$ and $13.2 \pm 0.7^{\circ} \mathrm{C}$ at 1 -, 2 - and 5-min points, respectively), followed by the FST with polyethylene gloves $\left(16.7 \pm 1.7,14.4 \pm 0.9\right.$ and $12.5 \pm 0.5^{\circ} \mathrm{C}$ at $1-, 2-$ and $5-\min$ points, respectively) and the lowest with bare hands (14.6 \pm 


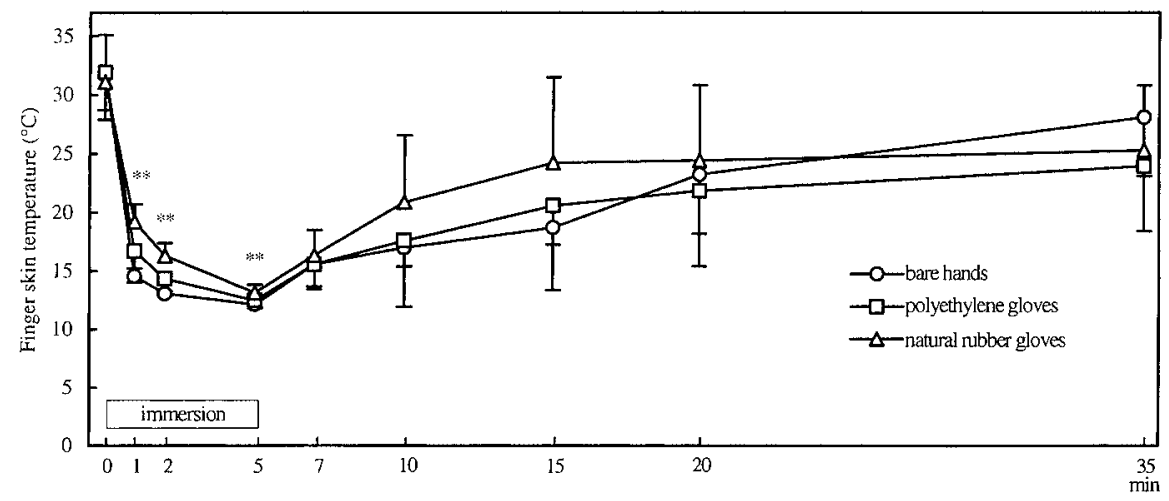

Fig. 2. Finger skin temperature of the right middle finger during immersion tests with bare hands, polyethylene gloves, and natural rubber gloves at immersion.

Pre-immersion $5^{\text {th }}$ min recording is shown as 0 in $\mathrm{x}$-axis. Data are mean $\pm \mathrm{SD}$. *** $p<0.01$ (among three conditions).

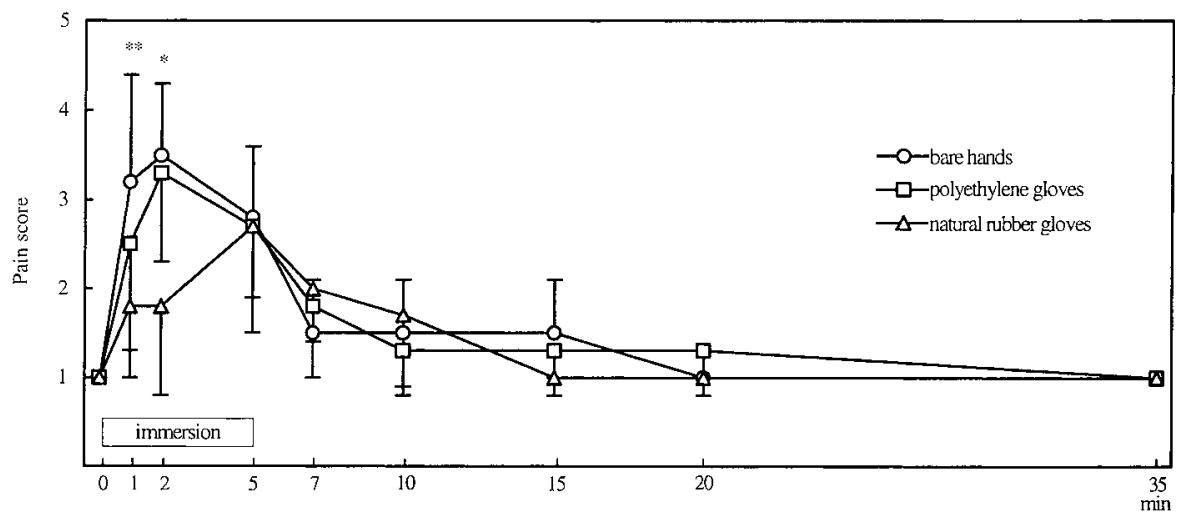

Fig. 3. Subjective pain scores for hand pain during immersion tests with bare hands, polyethylene gloves, and natural rubber gloves at immersion.

Pre-immersion $5^{\text {th }}$ min recording is shown as 0 in $\mathrm{x}$-axis. Data are mean $\pm \mathrm{SD}$. $*: p<0.05$, **: $p<0.01$ (among three conditions).

$0.5,13.1 \pm 0.2$ and $12.2 \pm 0.2^{\circ} \mathrm{C}$ at $1-, 2$ - and 5-min points, respectively).

Fig. 3 shows the subjective pain scores for hand pain during immersion tests with different conditions. The observed suffering showed the highest pain score at 2-min point followed by 1-min point when the test was with bare hands. Significant differences in pain score among three conditions at 1 - and 2 -min points ( $\mathrm{p}<0.01$ and $\mathrm{p}<0.05$, respectively) during immersion were observed showing the lowest pain score with natural rubber gloves $(1.8 \pm 0.8$ and $1.8 \pm 1.0$ at 1 - and 2-min points, respectively), followed by the pain score with polyethylene gloves $(2.5 \pm 1.2$ and $3.3 \pm 1.0$ at 1 - and 2-min points, respectively) and the highest with bare hands (3.2 \pm 1.2 and $3.5 \pm 0.8$ at 1- and 2-min points, respectively).

Suffering during immersion test becomes more severe in inverse proportion to the water temperature ${ }^{4}$. Therefore, high water temperature and shorter immersion time are desirable so that subjects avoid having to suffer while sufficient data for diagnostic value are obtained. Currently, in Japan, disturbance of the peripheral circulation is assessed by a cold-stress test involving immersion of one hand in cold water at $10^{\circ} \mathrm{C}$ for $10 \mathrm{~min}^{1,8,9)}$. In a study with two immersion tests conducted on same subjects consisting of a group of HAVS patients and a group of healthy controls, one test involving water at $10^{\circ} \mathrm{C}$ for $10 \mathrm{~min}$ and the other involving water at $15^{\circ} \mathrm{C}$ for $3 \mathrm{~min}$, the former test revealed a significant group difference between patients and controls; however, the later test $\operatorname{did}_{\text {not }}{ }^{10}$. Subject experiences considerable suffering during immersion test involving water at $10^{\circ} \mathrm{C}$ for $10 \mathrm{~min}$. In the ISO proposal, a water temperature 
of $12^{\circ} \mathrm{C}$ and an immersion period of $5 \mathrm{~min}$ are proposed at present for the standard method parameters to provide useful measurements while minimizing stress ${ }^{4}$. Subjects suffering can be reduced using waterproof covering at immersion. The waterproof covering should have high thermal conductivity and be tight enough to avoid trapped air during immersion ${ }^{4)}$. We examined the influence of waterproof covering (polyethylene and natural rubber gloves) on FST and subjective hand pain during immersion test on the same subjects.

A significant influence of subjects on FST at 1- and 5min points for the left hand and at 5-min point for the right hand during immersion was observed (not shown). However, it did not affect the influence of conditions on FST as the influences of conditions and subjects on FST determined by the statistical procedure used in the present study were independent ${ }^{7,11}$. There were significant differences in FST among three conditions during immersion showing the highest FST with natural rubber gloves, followed by the FST with polyethylene gloves and the lowest with bare hands. In other words, the effect of hand cooling during immersion period was the highest with bare hands followed by the condition with polyethylene gloves. There were significant differences also in pain score among three conditions during immersion showing the lowest pain score with natural rubber gloves, followed by the pain score with polyethylene gloves and the highest with bare hands. Severity of pain during immersion period, particularly 1 - and 2 -min points, was important because the condition of bare hands showed the highest pain score at 1- and 2-min points. For natural rubber gloves, pain score at the starting of the immersion during immersion test was small. The effect of hand cooling with natural rubber gloves during immersion period was low, because of lower thermal conductivity. Immersion test with polyethylene gloves showed pain score lower than that with condition of bare hands at 1- and 2-min points during immersion period. Therefore, immersion test with polyethylene gloves instead of bare hands during immersion seems to be suitable for reducing subject suffering. Further investigation on HAVS patients to validate the use of immersion test with polyethylene or similar gloves in obtaining sufficient data for diagnostic value is required.

\section{Acknowledgement}

We would like to thank Dr Md Shawkatuzzaman Laskar, postdoctoral research fellow of Japan Society for the Promotion of Science, for his support throughout the drafting of this article.

\section{References}

1) Harada N, Yoshimura M, Laskar MS (1999) A minireview of studies conducted in Japan using finger-skin temperature during cold-stress tests for the diagnosis of hand-arm vibration syndrome. Int Arch Occup Environ Health 72, 330-4.

2) Harada $N$ (2002) Cold-stress tests involving finger skin temperature measurement for evaluation of vascular disorders in hand-arm vibration syndrome: review of the literature. Int Arch Occup Environ Health 75, 14-9.

3) Harada N, Iwamoto M, Laskar MS, Hirosawa I, Nakamoto M, Shirono S, Wakui T (1998) Effects of room temperature, seasonal condition and food intake on finger skin temperature during cold exposure test for diagnosing hand-arm vibration syndrome. Ind Health 36, 166-70.

4) ISO/CD 14835-1 (2001) Mechanical vibration and shock-Cold provocation tests for the assessment of peripheral vascular function-Part 1: Measurement and evaluation of finger skin temperature. ISO/TC 108/SC 4/WG 11.

5) Kent P, Wilkinson D, Parkin A, Kester RC (1991) Comparing subjective and objective assessments of the severity of vibration induced white finger. J Biomed Eng 13, 260-2.

6) Lindsell CJ, Griffin MJ (2001) Interpretation of the finger skin temperature response to cold provocation. Int Arch Occup Environ Health 74, 325-35.

7) SPSS Inc (2001) SPSS advanced models ${ }^{\mathrm{TM}} 11.0 \mathrm{~J}$. SPSS Inc., Chicago.

8) Harada N, Matsumoto $T$ (1984) Validity of various function tests performed in Japan as a screening test for vibration syndrome. Int Arch Occup Environ Health 54, 283-93.

9) Harada N (1987) Esthesiometry, nail compression and other function tests used in Japan for evaluating the hand-arm vibration syndrome. Scand J Work Environ Health 13, 330-3.

10) Yoshimura M, Laskar MS, Shirono S, Iwamoto M, Harada N (2000) Finger skin temperature during coldstress tests involving water at $10^{\circ} \mathrm{C}$ for 10 minutes and at $15^{\circ} \mathrm{C}$ for 3 minutes for diagnosis of hand-arm vibration syndrome. In: Proceedings, $35^{\text {th }}$ Meeting of the United Kingdom Group on Human Response to Vibration, Southampton, 51-3.

11) Dupont WD (2002) Statistical modeling for biomedical researchers. $1^{\text {st }}$ ed., 335-6, Cambridge University Press, Cambridge. 